INTERNATIONAL JOURNAL OF SYSTEMATIC BACTERIOLOGY

Vol. 16, No 2 April 1966 pp. 145-149

\title{
RECOMMENDED DESIGNATIONS FOR THE SUBSEROTYPES OF SHIGELLA FLEXNERI
}

William H. Ewing ${ }^{1}$ and K. Patricia Carpenter ${ }^{2}$

SUMMARY. Recommendations are made regarding the designations applied to the serotypes of Shigella flexneri, and certain changes are recommended in those applied to subserotypes of S. flexneri 3 .

The use of abbreviated antigenic formulas, in addition to alphabetic designations, is recommended when reporting subserotypes of S. flexneri.

The purpose of this communication is to make recommendations regarding the manner in which subserotypes of Shigella flexneri should be designated and reported. Special reference is made to the subserotypes of $\mathrm{S}$. flexneri 3 .

Boyd (1940) substituted the Roman numerals I, II, and III for the alphabetic designations $\mathrm{V}, \mathrm{W}$, and $\mathrm{Z}$ employed by Andrewes and Inman (1919) and others and extended the number of recognized serotypes to include IV(103), V(119), and $\mathrm{VI}(88$, Newcastle, and Manchester). Andrewes and Inman, Boyd and others also recognized subserotypes within certain of the serotypes but did not propose particular designations for them.

Wheeler (1944) also used Roman numerals to designate the six principal se rotypes of $\underline{S}$. flexneri and introduced the use of lower-case Roman letters to designate two subsero-

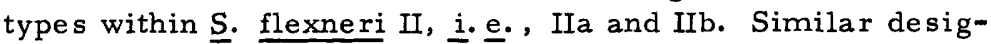
nations later we re employed by Wheeler (personal communications 1944,1946 ) to subserotypes of $\underline{S}$. flexneri I ( $\mathrm{Ia}$ and Ib) and S. flexneri IV (IVia and IVb). The serotype and subserotype designations employed by Boyd and by Wheeler were adopted by Ewing (1944), Kauffmann and Ferguson

\footnotetext{
International Shigella Center (Atlanta), Communicable Disease Center, Public Health Service, U. S. Department of Health, Education and Welfare, Atlanta, Georgia.

2 International Shigella Center (London), Central Publ. Hlth. Laboratory, Colindale Ave.., London NW 9, England.
} 
(1948), and by Ewing (1949). These designations also were used in recommendations made by the Shigella Commission of the Enterobacteriaceae Subcommittee of the International Committee on Bacteriological Nomenclature regarding $\underline{\mathbf{S}}$. flexneri (vide 1950 and 1953 Reports of the Enterobacteriaceae Subcommittee, published 1954) except that the Shigella Commission recommended the use of Arabic numerals rather than Roman ones to designate the various serotypes of Shigella, including $\underline{S}$. flexneri serotypes. This usage was applied only to serotype designations (e.g. , S. flexneri 2a) for use in reporting cultures and did not apply to the designations given to the individual type-specific antigens of Shigella strains, for which the use of Roman numerals was retained. The group-antigen factors and complexes continue to be designated by Arabic numerals.

The accepted serotypes and subserotypes of $\underline{S}$. flexneri are listed in Table 1 together with the reactions that may be expected with properly absorbed antisera. Also abbreviated antigenic formulae based upon antigenic structure are given in the table. The uses of abbreviated formulae in reporting results of typing was recommended by one of the authors in 1949 because they provide a further characterization of strains and provide a means of demonstrating to bacteriologists, epidemiologists, and others how cultures from various sources may differ.

In the 1958 Report of the Enterobacteriaceae Subcommittee, three subserotypes of $\underline{S}$. flexneri 3 were added to the Shigella schema: S. flexneri $3 a, 3 b$, and $3 c$. Experience has shown that these are valid, antigenically distinct subserotypes that are of importance not only epidemiologically but taxonomically as well. However, changes in the application of the designations $3 a$ and $3 b$ are necessary for purposes of clarity. Attention is directed to the fact that in a supplement to the 1958 Report of the Enterobacteriaceae Subcommittee, $\underline{S}$. flexneri 3 b was characterized as having group complex $\overline{3}, 4$ in addition to the 6 factor and the 7,8 complex, while in Table 1 of this paper, subserotype $3 \mathrm{~b}$ is listed as one that possesses group complex 3,4 and factor 6 but lacks the 7,8 complex. It is recommended that strains having the formula III:3,4:6... should be designated $\underline{S}$. flexneri $3 \mathrm{~b}$, as in Table 1 , since the presence of the 3,4 complex and the absence of the 7,8 complex are constant in this particular subserotype designated $3 \mathrm{~b}$ in the supplement to the 1958 Report. Cultures of $\underline{S}$. flexneri 3 that possess group complex 3,4 in addition to factor 6 and the $7,8 \mathrm{com}$ - 
TABLE 1

Shigella flexneri serotypes and subserotypes

\begin{tabular}{|c|c|c|c|c|c|c|c|c|c|c|c|}
\hline \multirow[b]{2}{*}{ Serotype } & \multirow{2}{*}{$\begin{array}{l}\text { Subsero- } \\
\text { type }\end{array}$} & \multirow{2}{*}{$\begin{array}{l}\text { Abbreviated } \\
\text { antigenic } \\
\text { formula }\end{array}$} & \multicolumn{9}{|c|}{ Absorbed antisera } \\
\hline & & & I & $\begin{array}{c}\text { Type } \\
\text { II }\end{array}$ & \multicolumn{2}{|c|}{ specific } & $\mathrm{v}$ & VI & \multicolumn{3}{|c|}{ Subserotype complexes or factors } \\
\hline \multirow[t]{2}{*}{1} & $1 \mathbf{a}$ & $I: 4 \ldots$ & $+*$ & - & - & - & - & - & + & - & - \\
\hline & $1 \mathrm{~b}$ & $I: 6 \ldots$ & + & - & - & - & - & - & - & + & - \\
\hline \multirow[t]{2}{*}{2} & $2 a$ & II $: 3,4 \ldots$ & - & + & - & - & - & - & +4 & - & \\
\hline & $2 b$ & II $: 7,8 \ldots$ & - & +4 & - & - & - & - & - & - & + \\
\hline \multirow[t]{3}{*}{3} & $3 a$ & III $: 6: 7,8 \ldots$ & - & - & + & - & - & - & - & + & + \\
\hline & $3 b$ & III $: 3,4: 6 \ldots$ & - & - & ++ & - & - & - & + & + & - \\
\hline & $3 c$ & III: $6 \ldots$ & - & - & + & - & - & - & - & + & - \\
\hline \multirow[t]{2}{*}{4} & $4 a$ & IV $: 3,4 \ldots$ & - & - & - & + & - & - & + & - & - \\
\hline & $4 \mathrm{~b}$ & IV: $6 \ldots$ & - & - & - & + & - & - & - & + & - \\
\hline 5 & 5 & $v: 7,8 \ldots$ & - & - & - & - & + & - & - & - & + \\
\hline 6 & 6 & vI:-... & - & - & - & - & - & +4 & - & - & - \\
\hline \multicolumn{2}{|c|}{ X variant } & $-: 7,8 \ldots$ & - & - & - & - & - & - & - & - & + \\
\hline \multicolumn{2}{|c|}{$Y$ variant } & $-: 3,4 \ldots$ & - & - & - & - & - & - & +4 & - & - \\
\hline
\end{tabular}

* Indicates degree of reaction: + rapid and complete, + weaker reaction, - no reaction (slide agglutination tests). 


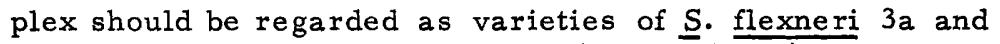

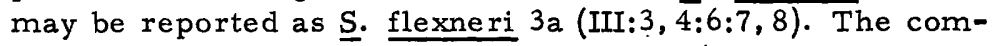
monly occurring variety of $\underline{\mathrm{S}}$. flexneri $3 \mathrm{a}$ (i. e., the classical Z) may be characterized by the abbreviated antigenic formula given for $3 a$ in Table 1. The earlier (1958) recommendation regarding subserotype $3 c$ remains unchanged. These may be reported S. flexneri 3c (III:6...).

While only the well known and accepted serotypes and subserotypes of $\underline{S}$. flexneri a re listed in Table 1 , it is known that varieties of several subserotypes occur that differ slightly from the usual either by possession of an additional group-antigenic factor or by the lack of one. Since characterization of such varieties may be of value and importance, particularly to epidemiology, it is recommended that these should be characterized by means of abbreviated antigenic formulae rather than by means of additional subserotypic designations such as $1 \mathrm{c}, 4 \mathrm{c}, 4 \mathrm{~d}, 4 \mathrm{e}$, as suggested by some writers. However, the factors or characters that make these subserotypic varieties different usually are variable or transitory, hence separate subserotype status should not be assigned to them. For example, a variety of subserotype $3 a$ that possesses the 3,4 complex was mentioned in the preceding paragraph. Others include varieties of $\underline{S}$. flexneri $l a$ and $4 a$ that contain small amounts of the 7,8 com-

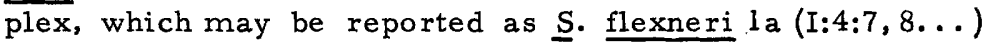
and $4 a(I V: 3,4: 7,8 \ldots)$, respectively. Also, some strains

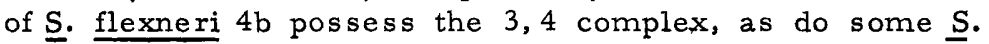
flexneri 6 cultures. These may be reported $\underline{S}$. flexneri 4 b (IV:3,4:6...) and S. flexneri 6 (VI:4...), respectively. Additionally, cultures that belong to serotypes 1,2 and 4 may be seen which, when they are freshly isolated, fail to react in slide tests in absorbed antiserum for the 3,4 complex. Generally, these may be shown to be $\underline{S}$. flexneri la, $2 a$, or $4 a$ by other methods. Similarly, S. flexneri 5 strains are seen that fail to react in absorbed 7,8 complex antiserum in slide-agglutination tests. However, the presence of this complex usually can be ascertained by examination of single colonies from platings.

Variant cultures in which type-s pecific antigen cannot be demonstrated may be reported as $\underline{S}$. flexneri $X$ variant $(-: 7,8, \ldots)$ or as $\underline{S}$. flexneri $Y$ variant $(-\overline{: 3,4 \ldots)}$. If subserotyping is not done, cultures may be reported simply as

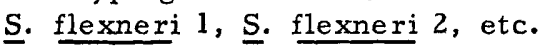

It must be emphasized that the antigenic formulas given in this paper are abbreviated ones, which employ the im- 
portant diagnostic antigens only, and are not intended to show the complete antigenic structure of $\underline{S}$. flexneri subse rotypes.

\section{REFERENCES}

Andrewes, F.W. and A. C. Inman. 1919. A study of the serological races of the Flexner group of dysentery bacilli. Med. Res. Council Spec. Rept. Ser., No. 42.

Boyd, J.S.K. 1940. The laboratory diagnosis of bacillary dysentery. Trans. Roy. Soc. Trop. Med. Hyg. 33:553571 .

Ewing, W.H. 1944. Rapid typing of shigellae. Jour. Bact. 48:703-704. - 1949. Shigella nomenclature. Jour. Bact. 57:633638.

Kauffmann, F. and W.W. Ferguson. 1948. Memorandum on the Flexner group. Acta Path. Microbiol. Scand. 25:621-622.

Reports, 1954. Enterobacteriaceae Subcommittee. Intern. Bull. Bact. Nomen. Tax. 4:1-45; 47-94.

Report, 1958. Enterobacteriaceae Subcommittee. Intern. Bull. Bact. Nomen. Tax. 8:25-70; 93-95.

Wheeler, K. M. 1944. Antigenic relationships of Shigella paradysenteriae. Jour. Immunol. 48:87-101. 
